\title{
Rock Mass Stability in the Southern New England Fold Belt, New South Wales, Australia
}

\author{
S.G. Fityus The University of Newcastle, Australia \\ J.H. Gibson The University of Newcastle, Australia
}

\begin{abstract}
The Southern New England Fold Belt of New South Wales in Australia is characterised by an arrangement of fault bound blocks of mildly deformed sedimentary rocks and interbedded volcanics. The geological blocks, which vary from hundreds of metres to tens of kilometres in extent, are bounded by faults that vary in width from metres to hundreds of metres. The strata may dip at any angle, but typically, the dips are in the range from 5 to 40 degrees. For strata dipping between 10 and 30 degrees, there are several examples of block sliding slope failures, where movement has occurred on surfaces parallel to bedding, allowing joint bounded blocks to separate to form cracks and chasms. In some cases, the areas affected are hundreds of metres wide, and the chasms are tens of metres deep. This paper describes two case studies of such occurrences. It explores the geological and topographical controls on stability and it identifies the relationships between geology and landform that are necessary to accommodate a kinematically admissible movement mechanism. Joints are found to be of similar importance to bedding in affecting rock mass stability. In particular, it is shown that the role of joints is more to act in combination than in isolation, and that the nature of this interaction may vary with position in order to achieve instability. It is noted that the presence of a greater number of different joint sets increases the likelihood of instability, as it facilitates a greater number of possible joint combinations.
\end{abstract}

\section{Introduction}

There is a substantial body of published research on the stability of slopes, spanning topics from engineering geology and geomorphology, to the application of GIS tools for risk management. The diversity of issues considered is a direct reflection of the diversity of challenging geological environments that confront engineering development. Indeed, the stability of slopes combines the dual challenges of climatic uncertainty and the inherent variability of geological environments.

Landslides are recognised in many parts of Australia (Fell, 1992). Cruden and Varnes (1996) present a classification for landslides, differentiating them firstly on the basis of material type and motion, with subsequent additional distinction on the basis of state, style, rate, etc. The literature contains case studies of all of the types identified by Cruden and Varnes (1996) and more, but it is interesting to note that, because of the unique set of conditions that control stability in different environments, generalised criteria with widespread applicability to many areas are few. Chowdhury and Flentje (2003) point out that "considerable knowledge and experience is required in order to identify the potential for the occurrence of different types of landslide events and the basic failure mechanisms associated with each of them." A significant contribution to that knowledge and experience is provided by the collective of published studies in the literature. However, papers describing or analysing sliding failures in rock masses are relatively uncommon.

This paper describes rock mass characteristics of two examples of rock mass instability in thickly bedded sandstones. It identifies the structural features that make such rockmasses susceptible to block sliding, and it recognises that the number and orientation of joint sets play an important role in the morphology of the slide and on slope stability. 


\section{The Paterson slide}

The Paterson Slide occurred in an area $2.5 \mathrm{~km}$ north-west of the township of Paterson as shown in Figure 1. It lies on the north-eastern side of a valley, where the ground slopes vary locally from about 10 to 30 degrees. It extends for a length of about $300 \mathrm{~m}$ across the slope, and the downslope width varies between 30 and $150 \mathrm{~m}$. Soils on these slopes are formed from the in situ weathering of sandstone rock. They are composed predominantly of silts and fine sands, with a minor clay fraction, and they have a typical depth of approximately $0.5 \mathrm{~m}$. On the opposite (stable) side of the valley, slopes are generally steeper, from 25 to 30 degrees, and the soil cover is thinner, with large areas of scattered rubble and rocky outcrop. The creek, which drains the valley to the north west, only dries out completely during extended periods without rain.

Vegetative cover varies across the property and is at different stages of revegetation maturity after the earlier extensive clearing. The sloping sides of the valley feature mixed eucalypt forest and thick undergrowth with the larger trees being predominantly ironbark species. The area affected by movement appears to be particularly suited to the growth of thick vegetation, making detailed mapping difficult. There remain significant cleared areas in the base of the valley where the ground slopes are more moderate.

\subsection{Geology}

The Paterson instability lies within the Carboniferous aged Mount Johnstone beds (Sussmilch and David, 1920) which were further defined as the Mount Johnstone formation by Hamilton et al. (1974) as belonging to the upper section the Carboniferous Period.

The sedimentary rock sequence in the valley containing the instability is approximately 200 metres thick, with the unstable strata being within the valley's basal units. Generally, these comprise red/brown to yellow coloured, thinly bedded, terrestrially deposited, medium grained sandstones from 1 to $3 \mathrm{~m}$ thick. They are interspersed with thinly laminated, very fine, fossiliferous (wood fragment prints) sandstone to siltstone beds up to $10 \mathrm{~cm}$ thick. One such layer visible amongst displaced blocks consists of a fine to very fine siltstone, containing numerous centimetre-sized mud clasts. Conglomerate stringers greater than $0.5 \mathrm{~m}$ thick are present but uncommon.

A difference in the weathering properties between the northern slopes of the valley, which contain the instability, and the steeper but stable southern slopes, is noted. The rocks of the southern slopes are generally medium to strong ignimbritic volcanics. The rocks of the northern slopes, while competent enough to form discrete blocks, are generally weak to friable, with the outcropping rock often crumbled by hand. Four bedding orientations were taken in a new excavation for a small dam, on the unaffected southern valley slope. The average strike of the beds is in the direction 120 to 300 degrees and dip was measured at 16 degrees to the south.

A study of the joints occurring within the rocks of the area was also undertaken. There are two major sets of penetrative, orthogonal, systematic joints and two minor sets of diagonal, systematic joints that do not appear to penetrate the orthogonal system. Only a few non-systematic or curvi-planar joints were observed. Generally, the dominating orthogonal sets tended to form square or rectangular blocks, only occasionally disrupted by the diagonal joints. The orientations of 39 systematic joints were measured and are plotted in Figure 2(a).

\subsection{Morphology}

The Paterson Slide occurred by sliding of large joint-bounded sandstone blocks. It affected the southwestern facing slopes of a valley, produced a series of extension and compression features. The arrangement of slide features is shown in Figure 3. On the basis of the field mapping, it appears that two different areas of block sliding exist on the site. A deeper feature (up to $4 \mathrm{~m}$ ) consisting of a single chasm around $80 \mathrm{~m}$ long, occurs at an elevation of about $130 \mathrm{~m}$, adjacent to the upslope property boundary. A shallower (up to $2.5 \mathrm{~m}$ ), more extensive series of features wraps around the hill slopes from an elevation of about $80 \mathrm{~m}$ in the south, to about $115 \mathrm{~m}$ (Australian Height Datum) in the north. It is also noted that the upslope feature is mostly developed in what appears to be a single bed of sandstone up to $3 \mathrm{~m}$ thick, whereas the downslope features seem to extend down through a number of different sandstone units, each up to $2 \mathrm{~m}$ thick, separated by siltstones up to $150 \mathrm{~mm}$ thick. 


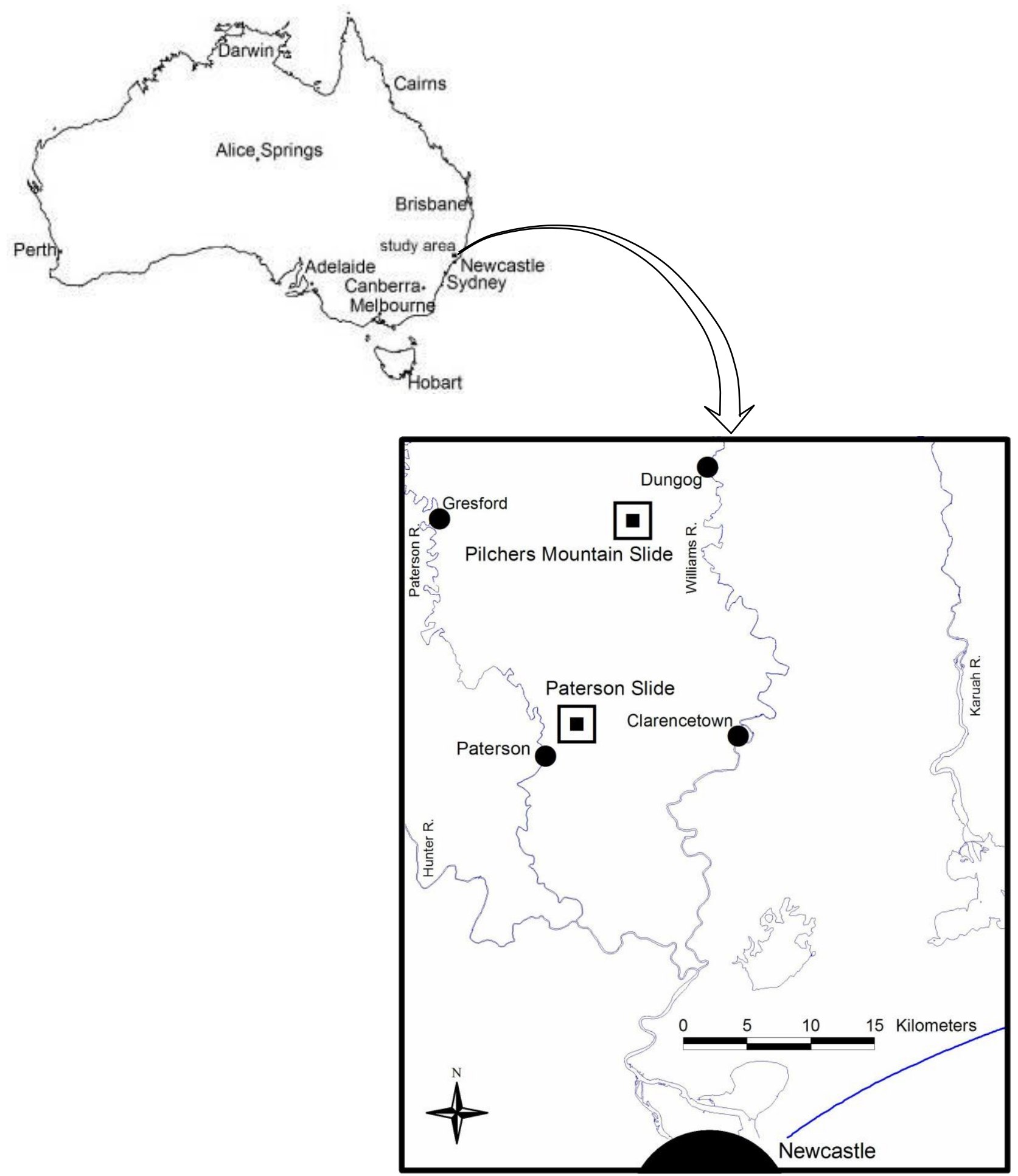

Figure 1 Locality sketch for the two cases considered in this study

Extension features appear to result from the translational spreading of the large, joint bounded sandstone blocks. The size of these blocks can exceed $5 \mathrm{~m}$, although they are typically of the order of 2 to $4 \mathrm{~m}$. Translation of adjacent blocks to differing extents results in the formation of sub-vertical openings between blocks. The measured strike trends of 94 extensional openings are plotted in Figure 2(b). It can be seen that the openings are relatively uniformly manifested in two principal strike directions, 010 and 115 degrees (see Figure 3). The translational movements usually involve a component of movement perpendicular to each of these directions, although translation in a direction orthogonal to the 115 degree trend is typically dominant. 


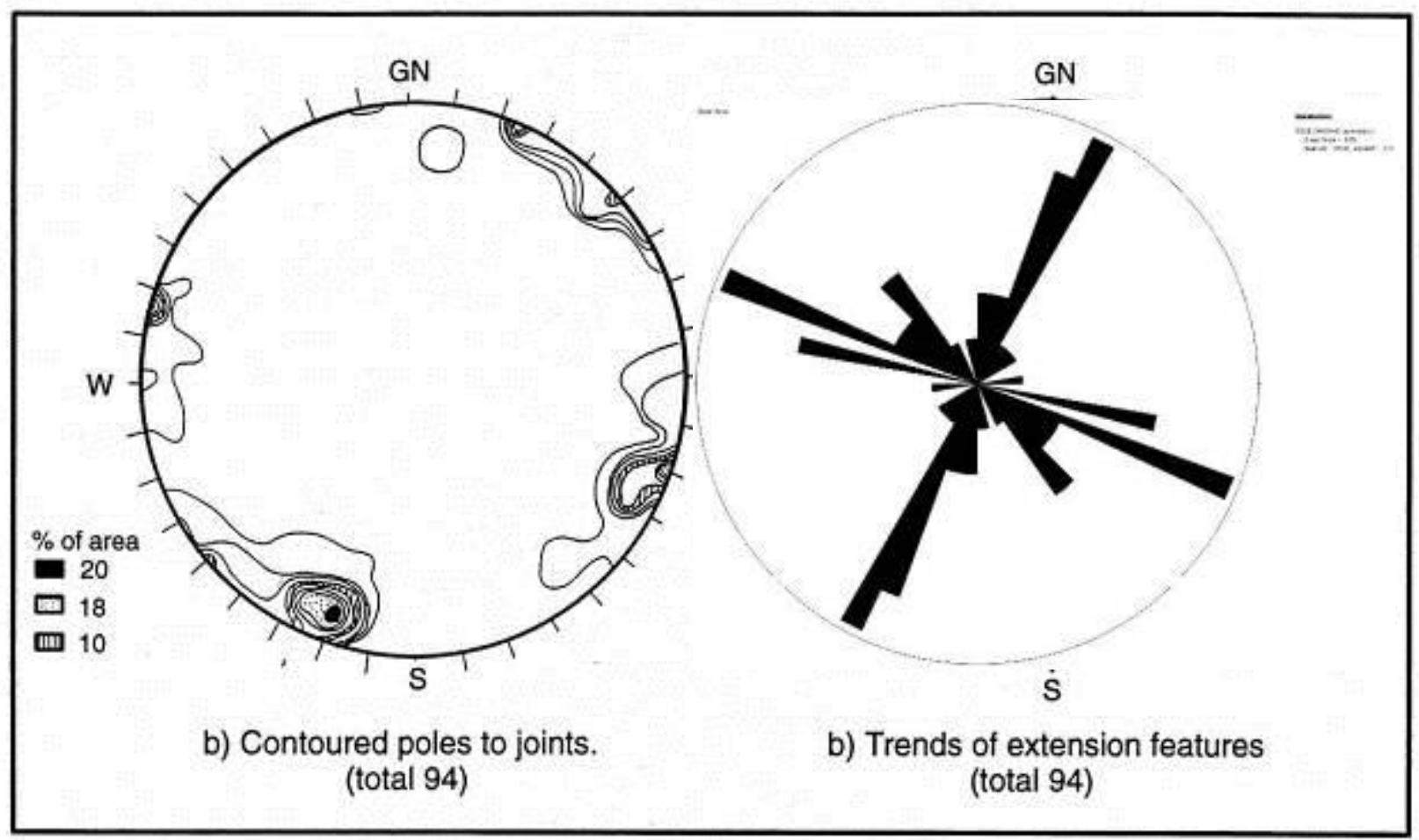

Figure 2 Distribution of joint planes at the Paterson slide (Fityus and Gibson, 2000)

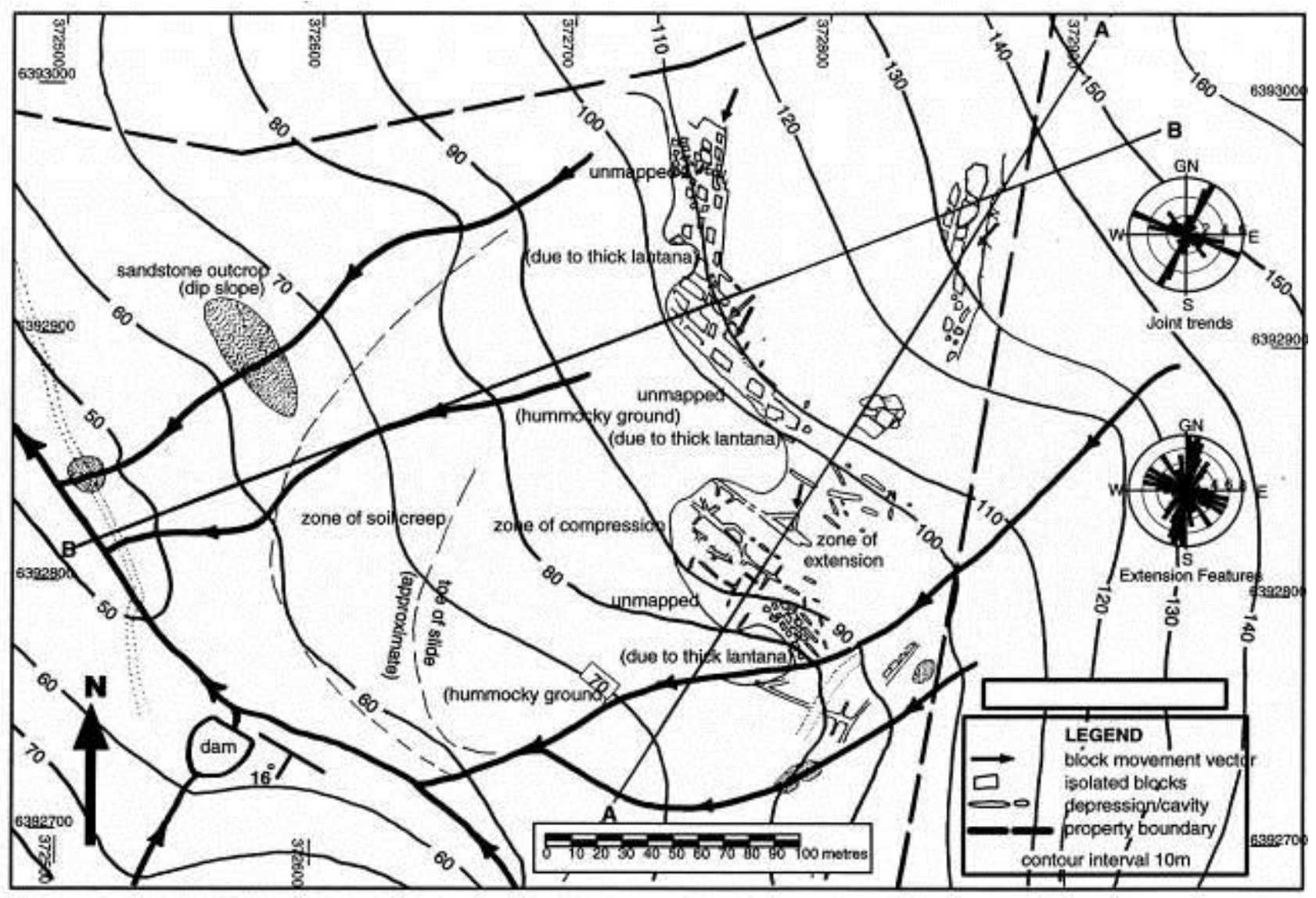

Figure 3 Size and extent of the Paterson slide (Fityus and Gibson, 2000) 
The tensional features produced by block translation may be classified in a number of ways, depending upon the extent and direction of block movement. Fityus and Gibson (2003) recognise four distinct types of tensional features. They are:

- Cavities: localised, sink-hole type features, produced where small translational movements occur to open joints in two directions. For small block separations, the soil is able to span the opening between block sides. Where two narrow openings intersect, the soil cover cannot span in two directions, and collapses to produce a localised cavity. They are typically less than one metre across.

- Depressions: linear, trench-like features, which form between separated blocks, where either the soil cover spans, but sags, or the soil both above and adjacent to the opening, collapses into the opening partially filling it. Depressions are typically less than $1 \mathrm{~m}$ wide and $0.5 \mathrm{~m}$ deep. Depressions may contain cavities.

- Chasms: occur where wide movements are principally in one direction only, leaving a deep, parallel sided opening between sandstone blocks. Chasms may be up to $6 \mathrm{~m}$ wide and up to $5 \mathrm{~m}$ deep.

- Isolated blocks: produced where translational movements are large enough to produce chasms simultaneously in two directions.

Compression features are mostly developed at the toe of the slide. These mostly comprise hummocky ground, with deeper soils and common scattered boulders and rock debris, mostly rotated. The amplitude of the hummocks is up to $1 \mathrm{~m}$. On the lower slopes, beneath the main slide area, there are areas of forest regrowth in which most of the trees show some degree of bowing or curvature in the lower part of their trunks. The ground in this area is not hummocky, but scattered loose rocks are common. Figure 4 shows two cross-sections through the slide affected area.

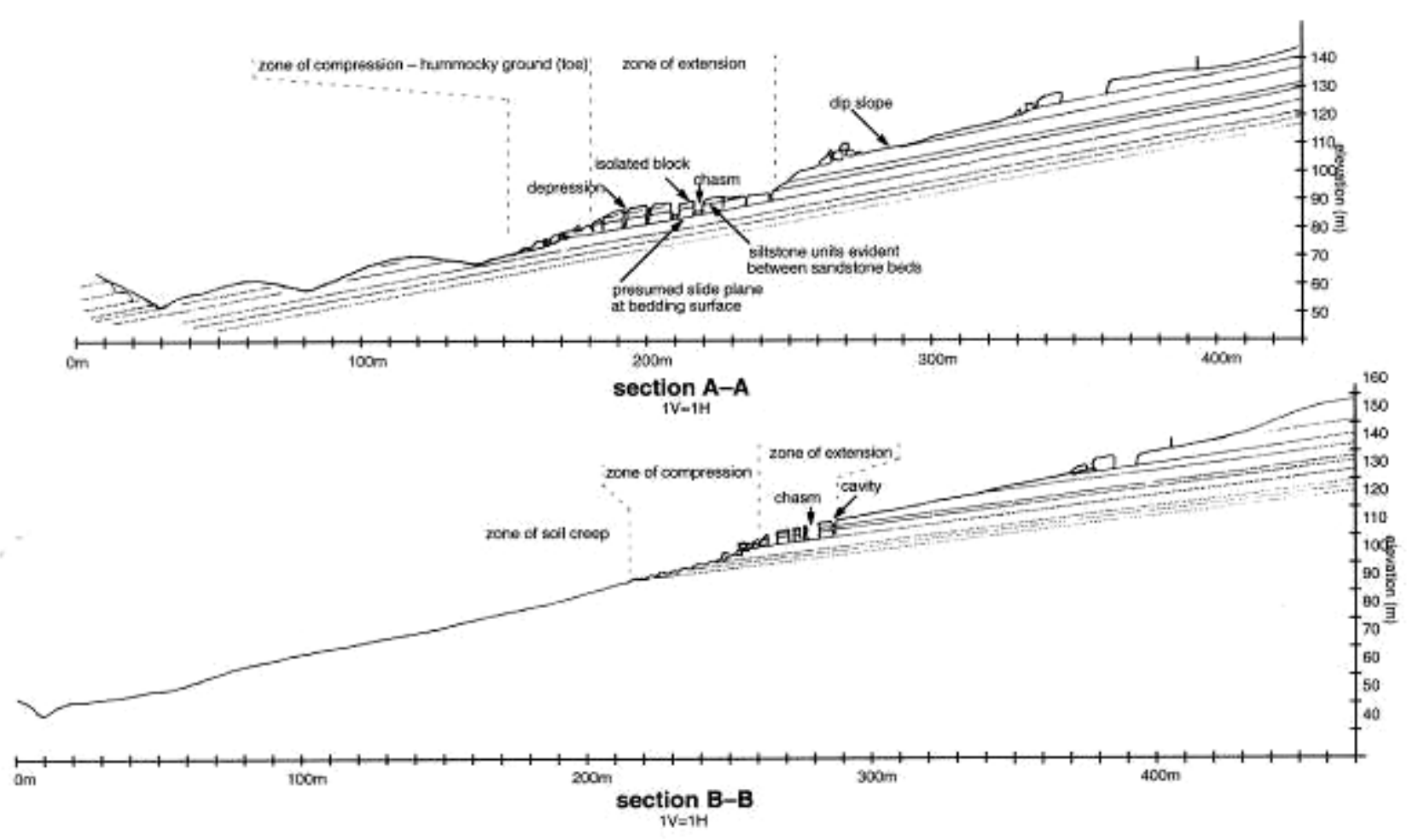

Figure 4 Cross-sections through the Paterson slide (Fityus and Gibson, 2000)

\subsection{Occurrence}

The Paterson slide occurred in 1927 . It is situated on a property which was progressively cleared for farming during a period from around 1900 to 1918 . It was originally virgin forest with eucalypt trees up to $30 \mathrm{~m}$ high, $0.5 \mathrm{~m}$ in diameter. 
Those who were in the area at the time of the movement in late April 1927, recalled that the period leading up to this event was exceptionally wet. Anecdotal accounts report that the slope failure produced a great noise which was heard from the railway station, over three kilometres away. Following the event, it was found that trees that were standing on the slope before the event were still standing when the movement ceased. A significant quantity of mud and water streamed from deep crevices, which were formed between massive blocks of rock with the soil and vegetation still standing on them. An extensive series of crevices, up to $6 \mathrm{~m}$ deep, remained in what had been a grassy slope. Following the event, stock grazing was abandoned, and the site was allowed to revegetate. There is no evidence to suggest that any further movement occurred after this.

\section{The Pilchers Hill slide}

The Pilchers Hill slide occurred in an area around $8 \mathrm{~km}$ southwest of the township of Dungog, as shown in Figure 1. It lies on the upper slopes of the southern side of a hill with a relatively complex topography. The hill structure, which is approximately triangular plan view, has relatively gentle but irregular concave slopes (20 degrees moderating to 15 degrees) to the northwest and steeper but more regular slopes (around 25 degrees) to the northeast. The south-facing slopes, which are affected by the instability, are seriously altered from their original form, but are likely to have originally sloped at around 15 degrees. At the southwestern corner, the hill extends across a small saddle to another, smaller knoll.

The slide extends for a length of about $700 \mathrm{~m}$ across the slope, and the downslope width is around $500 \mathrm{~m}$. Soils within the area occur sporadically in areas where they have not been eroded from the top of blocks, or are not obscured by rubble. They are composed predominantly of silts and sands, with a minor clay fraction.

Because of its south-facing aspect and the concentration of deep, damp spaces, the site has become vegetated with relatively dense temperate rainforest vegetation. This comprises tall evergreen trees including native figs, ferns, mosses, vines and orchids. The trees form a relatively dense canopy which hinders the use of GPS equipment and precludes the use of aerial photography as a mapping tool. Although the understorey is relatively open, mapping and fieldwork is further hindered by the difficult terrain and the noxious weed lantana, which grows dominantly in this environment.

\subsection{Geology}

The Pilchers Hill instability lies within the Carboniferous aged Wallaringa Formation (Roberts 1961) which has been dated as late Visean (343-325 Ma). This sedimentary rock formation is in excess of $300 \mathrm{~m}$ thick. Generally, these comprise beds of pale brown to pink coloured, thickly bedded, terrestrially deposited, medium to coarse grained sandstones, up to $5 \mathrm{~m}$ thick. The sandstones are made up of poorly sorted, angular to sub-angular grains of quartz, plagioclase and rock fragments with a laumontite cement. Beds are poorly defined, except for occasional minor thinly-laminated, siltstone beds, which may be carbonaceous. These are up to $250 \mathrm{~mm}$ thick, and contain occasional lycopod log prints. Erratic conglomerate lag deposits up to $1 \mathrm{~m}$ thick are present in the western end of the instability feature.

The sandstones are mostly highly to moderately weathered, and whilst often weak to friable, they are generally competent enough to form large discrete blocks, that may stand freely to considerable height.

Bedding orientations measured on several of the siltstone interbeds, and occasionally on sandstone bed surfaces, gave dip directions ranging between 205 and 245 degrees, with a mean direction of around 220 degrees. Strata dip measurements ranged between 4 and 15 degrees, with a mean value of around 10 degrees. There is some suggestion that the dip is slightly greater than 10 degrees (12 degrees) in the west, and slightly less than 10 degrees (8-9 degrees) in the east.

A study of 79 joints exposed in the uppermost (stable) scarp reveals that joints with a wide range of orientations are present in the area. In summary, major sets of sub-orthogonal joints are developed in the 160-340 and 80-260 degree directions; minor sets of joints are developed in the 000-180, 100-280, 110-290 and 120-300 degree directions; and joints are notably absent in NNW-SSE and ENE-WSW directions. In general these joints are vertical or sub-vertical (steeper than 80 degrees). The orientations of the 79 systematically measured joints are plotted in Figure 5. 


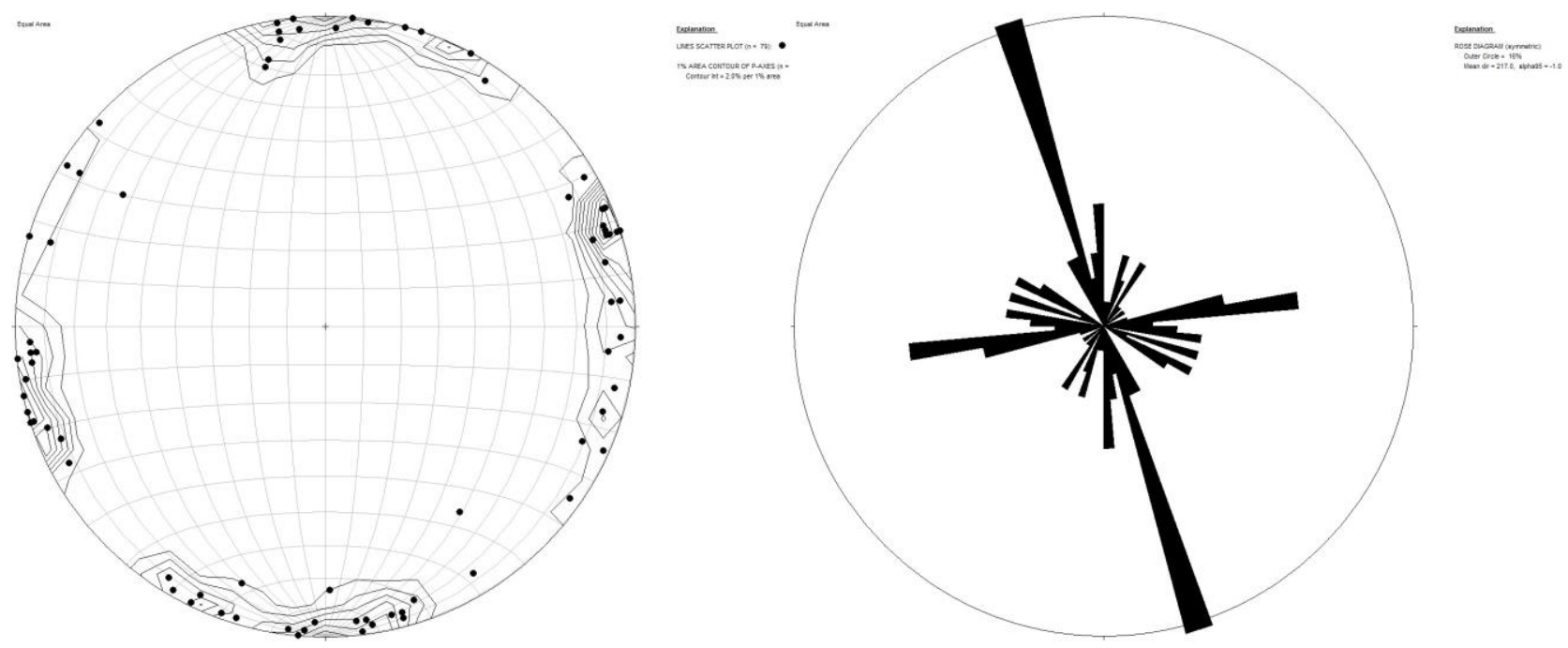

Figure 5 Distribution of joint planes at the Paterson slide

\subsection{Morphology}

The Pilchers Hill slide is developed as a series of slices of a thick, gently dipping sandstone bed. The axes of the slices are aligned approximately parallel to the strike of the ground surface, and they appear to have separated through translation in an approximately downslope direction. The general arrangement is illustrated in Figure 6, and a cross-section of the slide is reproduced in Figure 7(c). In all, five main slices are identified. The upslope slices are massive, often well-formed, in-tact blocks of sandstone that appear to have separated along joints. A typical well-formed block from the upper slice is shown in Figure 8(a). The form of the slices deteriorates progressively, in a succession toward the bottom of the slope, so that the lowermost slice is little more than a pile of coarse sandstone block rubble (see Figure 7(c)).

The relative displacements of blocks within the slide are complex. In some areas, it is possible to speculate on how the movement of adjacent slices might be reversed to re-assemble the ground surface to a pre-failure condition, however, in most areas, partial or complete collapse of isolated blocks has made such an assessment impossible.

The uppermost scarp, which is presumed to be formed in rock that has not yet moved, is clearly formed from the intersection of many vertical and sub vertical joint planes. The chasms that are formed by this scarp and the adjacent downslope slice are from 3 to $10 \mathrm{~m}$ wide, and have open depths of up to $15 \mathrm{~m}$. A photograph showing a deep, narrow chasm is presented in Figure 8(b). Smith (2007) describes a number of tectonic caves that exist in the base of the chasms, formed within a considerable thickness of large block rubble that is present in the bottom of chasms in most areas. He reports that the base of the deepest cave is around $32 \mathrm{~m}$ below the top of the adjacent scarp, suggesting that the slide is occurring on a deep-seated slide plane, affecting a sequence of sandstone beds greater than $30 \mathrm{~m}$ thick.

The morphology of the uppermost scarp has been mapped in detail using tape and compass techniques. Two larger blocks in the first slice have been mapped in detail, but considerable further work remains to complete detailed mapping of the entire slide affected area.

\subsection{Occurrence}

As far as the authors are aware, there are no factual accounts of the occurrence of the Pilchers Hill slide. The distribution and maturity of the vegetation suggests that the feature is likely to be relatively ancient, and it is almost certain that most of the movement occurred prior to white settlement of Australia. There is no evidence to suggest that any movements have occurred in recorded history. 


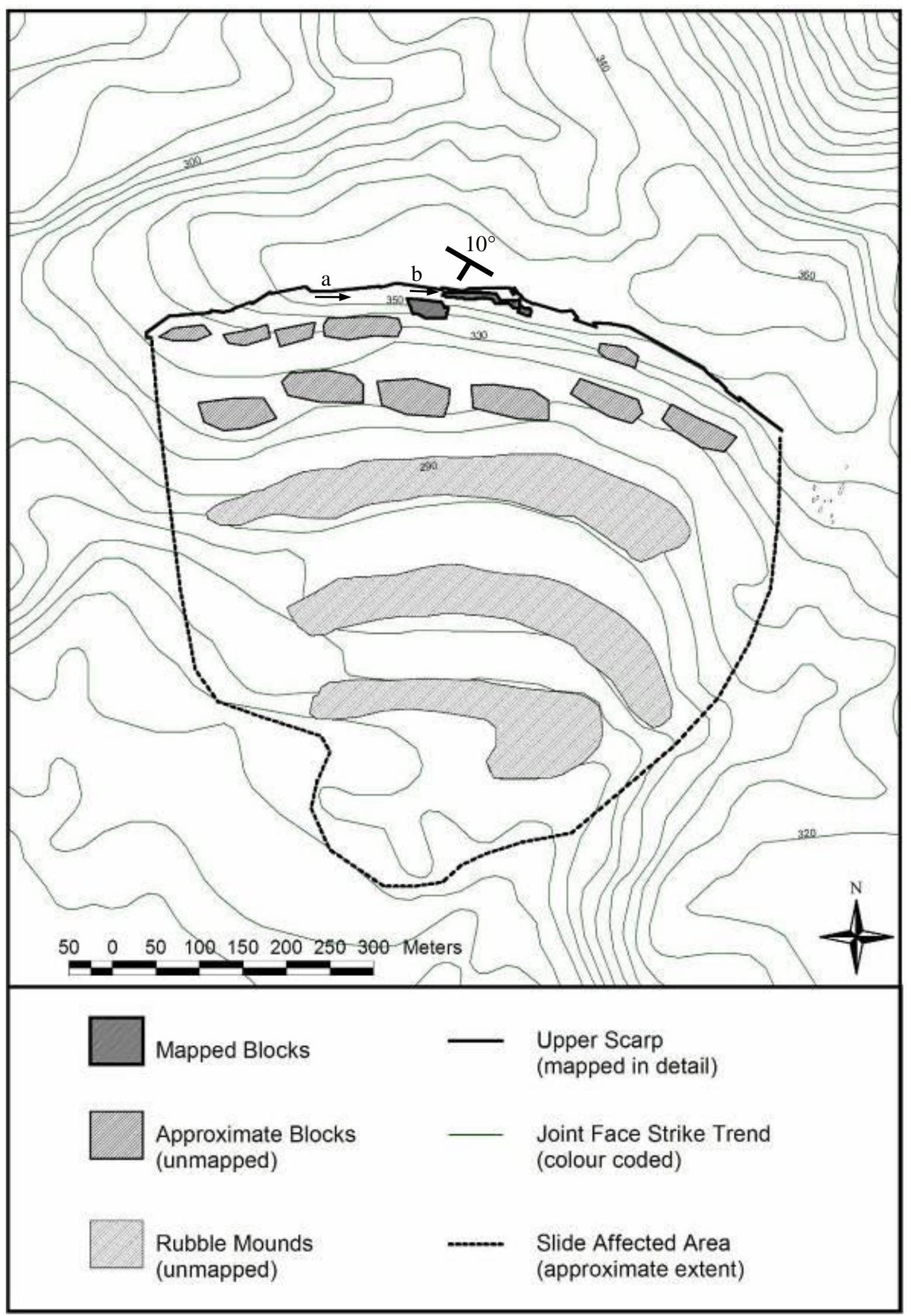

Figure 6 Approximate size and extent of the Pilchers Hill slide 


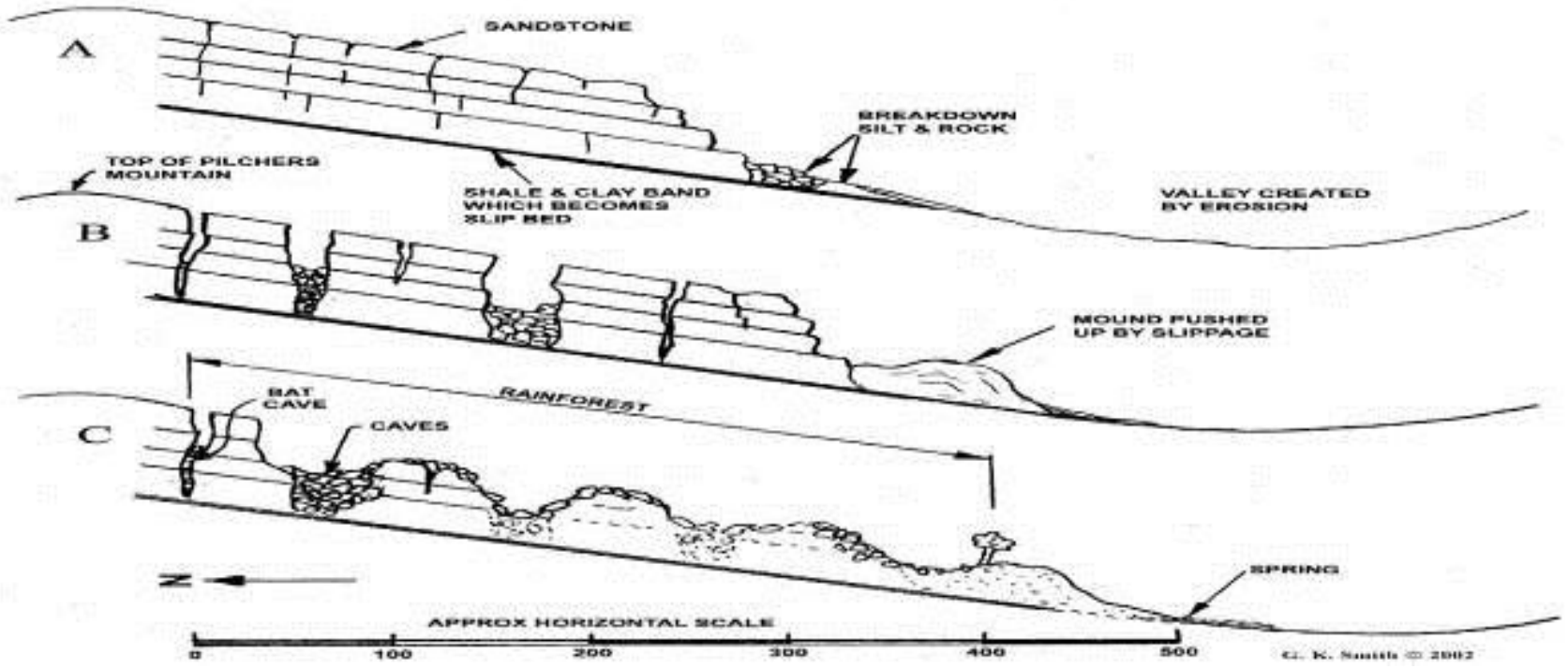

Figure 7 Cross-sections through the Pilchers Hill slide (after Smith, 2007 - note that the figure has been compressed vertically so that it is close to natural scale)

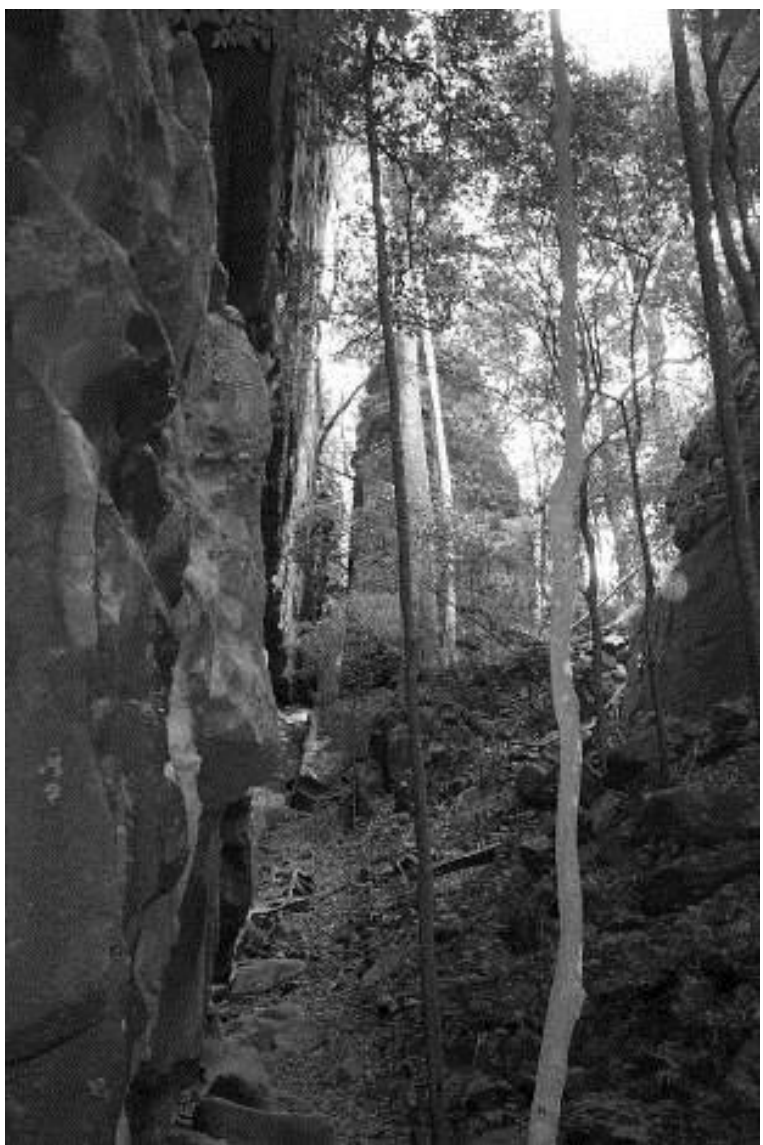

(a)

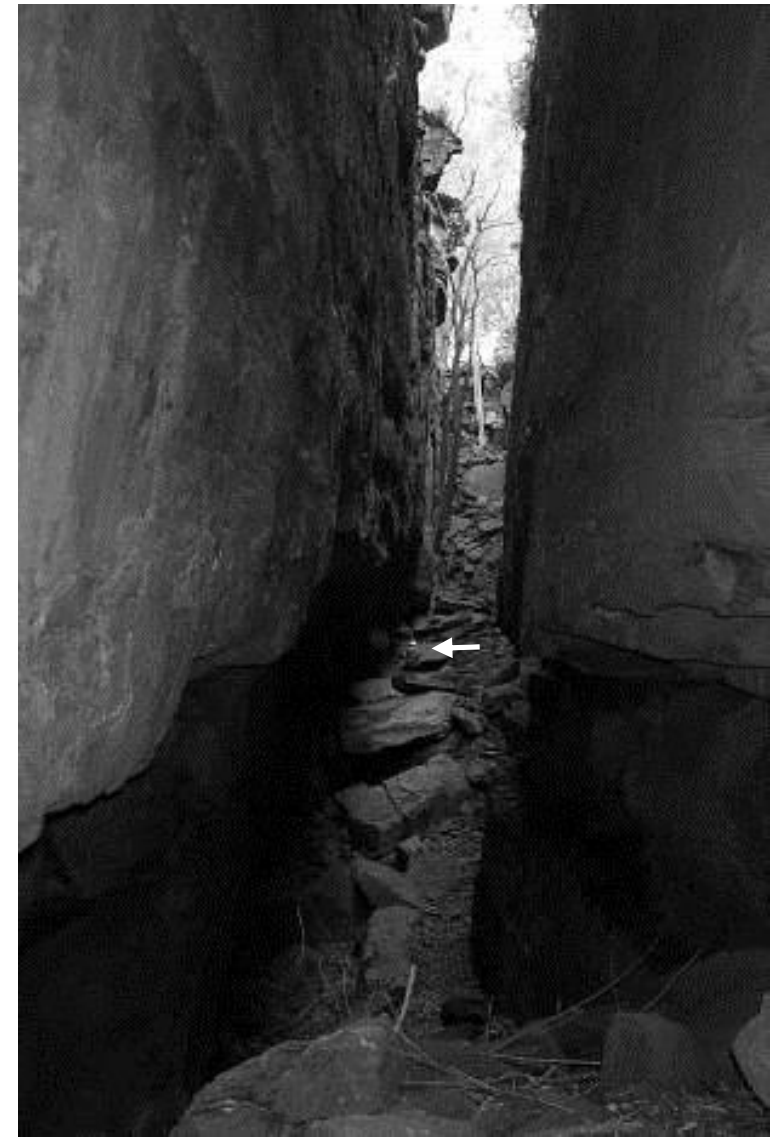

(b)

Figure 8 Photographs of uppermost chasms, looking west; a) chasm between the stable scarp on the left, and a free standing block on the right; b) $3 \mathrm{~m}$ wide chasm with stable scarp on the left, and displaced block on the right. Note the adult in the bottom of the chasm (white arrow) Photographs are taken from positions a and $\mathrm{b}$ as indicated in Figure 6 


\section{Discussion and analysis}

The style of sliding studied in this paper is best described as rock sliding, according to Cruden and Varnes (1996), although this description is not ideal. It can also be described as block sliding, or block gliding: "a process in which the mass progress out, or down and out, as a unit along a more or less planar surface" (Watson and Wright, 1963); though even this definition can encompass a wide range of styles. Studies of block slides/glides, though not infrequent, are less common in the literature than studies involving soil slides or rock falls. Studies involving sliding on bedding planes are less common still. Notable examples of bedding plane block slides include the Waikaremoana landslide (Davies et al., 2006); the Chuska Mountain slides (Watson and Wright, 1963), the Olean Rock City slide (Radbruch-Hall et al., 1982) and the Kitnayakwa River slide (FSBC, 2002). The last two of these are classified as "sackungen", which are described as topographic structures characterised by grabens on the tops of ridges and associated uphillfacing scarps on ridge sides, both of gravitational origin (Radbruch-Hall et al., 1982) or uphill-facing scarps and troughs parallel to ground contours (FSBC, 2002). The detailed differences between these superficially similar slides demonstrates the incomplete state of knowledge of the nature of bedding-plane block slides, and the need for site-specific research to characterise the controlling factors in a particular region.

It is generally accepted that the factors that affect slope stability fall into three main groups: topographic factors (steepness, relief), geological factors (geological structure, geological strength, geological history) and climatic factors (rainfall, groundwater and erosion). All analyses consider topographic factors, as topography is needed to define a slope. In some studies, such as Clerici (2002) and Farina et al. (2004), the criteria for instability are based almost entirely on topographic or geomorphological considerations. In homogeneous soil materials, the assumption of arbitrary or generic failure surfaces may facilitate sufficiently accurate assessments of stability, where the critical parameter is topographic slope. However, while topographic slope is an important factor in rock slopes, geological structure is also critical.

In almost all cases, rainfall and elevated ground water levels play a role as triggers for slope instability events. However, in the case of rock slopes, these are relatively unimportant, unless the combination of topography and geological structure can result in a kinematically admissible failure mechanism. In each of the two cases studied here, this is clearly the case. The most essential condition for a kinematically admissible failure mechanism is to have bedding planes (or some other pervasive, low-angle discontinuity), which are closely related to the ground surface. This relationship has a number of essential aspects: the dip direction of the geological surface (potential slide plane) and the ground surface must be in the same general direction, so that translational movement of an unstable rock mass can occur in a downslope direction; the geological surface should be steep enough so that the downslope weight component is great enough to overcome friction; the slope of the geological surface should be low enough that it is less than the ground slope, and hence can 'daylight' somewhere at the ground surface. In the case of the Paterson slide, bedding within the sandstones dipped at around 16 degrees in the direction of 210 degrees. The ground surface of the unstable area has an average slope of around 14 degees in the general direction of 240 degrees, but it steepens locally to as much as 20 degrees, and movement is restricted to the steeper areas of the slope. In the case of the Pilchers Hill slide, bedding within the sandstones dipped at around 10 degrees in the direction of 220 degrees. It is estimated that the original ground surface of the unstable area had an average slope of around 15 degrees in the general direction of 190 degrees. In both of these cases, whilst bedding slope was (at least locally) less than the ground slope, it is interesting to note that the dip directions of bedding and topography differed by around 30 degrees. It is also interesting to note, in the case of the Paterson slide (where observations were possible), that slide movements, as interpreted from the displacement of blocks relative to their original positions against the stable scarp, appear to have occurred primarily in the direction of steepest bedding dip (as expected), and not in the direction of the steepest topographic slope.

It is likely that the point of instability is a finely balanced equilibrium of slope forces. Tending to destabilise the slope, are forces due to block weight and perhaps, water pressures. Stabilising forces come from friction between the potentially unstable blocks and the underlying beds, and mechanical interference between the potentially unstable blocks and adjacent blocks that are inherently stable. The restraint provided through mechanical interference is relatively great, and so, it is reasonable to presume that an additional condition to achieve a kinematically admissible failure mechanism is the ability for the movement to occur in a direction such that the failure scarps that release the unstable mass, can form by simply pulling apart, without requiring fracturing or sliding along vertical joint surfaces within the rock mass. This has two implications 
in regard to the importance of rock structure. First, the likelihood that such a condition can be achieved increases as the number of joint sets in the rock mass increases. Second, since the gross movement characteristics are governed by topography and bedding, the possible/likely location of failure scarps is somewhat constrained, and it is likely to be necessary that more than one set of joints be involved in achieving an interference-free scarp along which, the sliding mass can be released.

In the case of the Paterson slide, it appears that the two dominant joint sets have mostly been able to combine to achieve this condition, although there is some suggestion that a third and perhaps, a fourth set have made some contribution. In the case of the Pilchers Hill slide, at least five significant joint sets are recognised, and some of these could be further differentiated. Figure 9 provides an analysis of the joint planes that have combined to form the main scarp at the crest of the slide. To facilitate a visual analysis, the joints in the scarp are emphasised, to illustrate their relation to those in the joint frequency diagram. The first observation afforded by Figure 9 is that the geometry of the scarp is complex and many different joint sets have combined to achieve an interference-free failure scarp. On closer inspection, it is apparent that different combinations of joints are needed to achieve the necessary scarp geometry throughout its length. To the west, a particular combination of four joints is mostly involved; in the centre, three different joints are involved; and to the east, 3 different joints again define the scarp. This result confirms that the geometry of slides in bedded sandstones is very strongly influenced by basic rock mass characteristics.

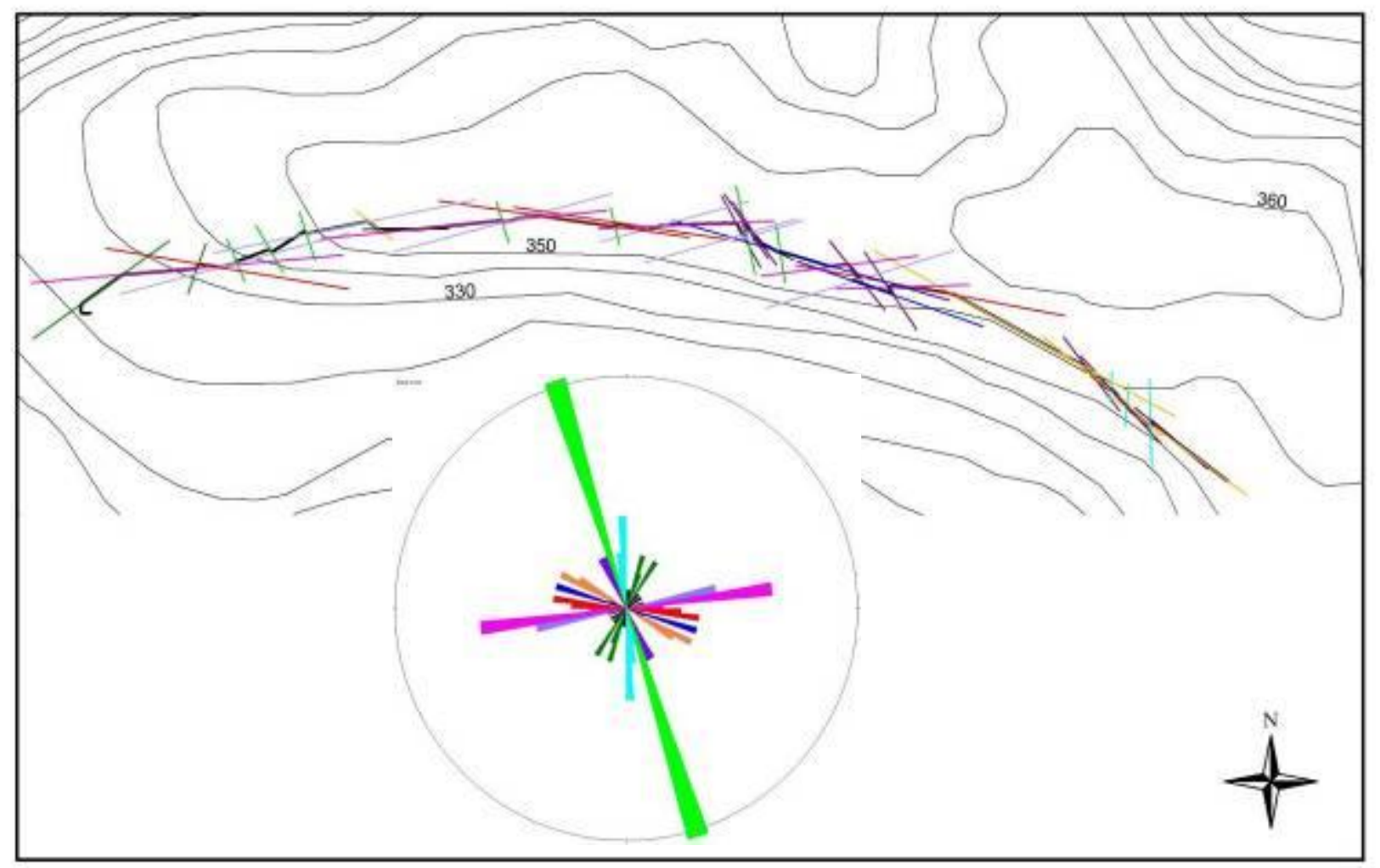

Figure 9 Analysis of the distribution of joint surfaces in the main failure scarp at Pilchers Hill

\section{Conclusions}

The stability of gently dipping bedded sandstones is primarily controlled by the basic rock mass characteristics of bedding and jointing. Through their interaction with the site topography, each of these plays an important role in achieving (or not) a kinematically admissible failure mechanism. Should such a mechanism exist, then the state of stability is further controlled by environmental factors such as the presence of vegetation and climatic events. 
This paper demonstrates that a good understanding of the structure of rock masses, and its implications for stability, is essential to the engineering and management of slopes, even in apparently simple sedimentary environments. Whilst this paper goes some way toward an improved appreciation of stability in such environments, there is a need for more detailed approaches to be developed for the assessment of stability for the conditions of gently dipping, shallow sedimentary rocks that dominate much of the east coast of Australia, and other parts of the world.

\section{Acknowledgements}

Thanks are extended to the owners of the property on which the Paterson slide occurs, and to the owners of the property from which the Pilchers Hill slide is accessed.

\section{References}

Chowdhury, R. and Flentje, P. (2003) Role of slope reliability analysis in landslide risk management. Bulletin of Engineering Geology and the Environment. Springer 62, pp. 41-46.

Clerici, A. (2002) A GRASS GIS based Shell script for Landslide Susceptibility zonation by the Conditional Analysis method. Proceedings Open source GIS - GRASS users conference. Trento, Italy.

Cruden, V.M. and Varnes, D.J. (1996) Landslide types and processes. Landslides: Investigation and mitigation, A.K. Turner and R.L. Schuster (editors), Special Report 247, Transport Research Board, Nat. Res. Council. Washington DC.

Davies, T.R., McSaveney, M.J. and Beetham, R.D. (2006) Rapid block glides: slide-surface fragmentation in New Zealand's Waikaremoana landslide Quarterly Journal of Engineering Geology and Hydrogeology, 39, pp. 115-129.

Farina, P., Moretti, S., Colombo, D., Fumagalli, A. and Manunta, P. (2004) Landslide Risk Analysis by means of Remote Sensing Techniques: Results from the ESA/SLAM Project Proceedings of International Geoscience and Remote Sensing Symposium. Germany, IEEE, pp. 62-65.

Fell, R. (1992) Theme Address - Landslides in Australia. Proceedings Sixth International Symposium on Landslides, Christchurch, February, Vol. No. 3, Balkema, pp. 2059-2100.

Fityus, S. and Gibson, J. (2000) Slope instability in thickly bedded Carboniferous sandstones. Proceedings of GEOENG 2000 (the millennium conference of ISSMGE, IAEG and ISRM), Melbourne.

FSBC (2002) Sackungen on a Forested Slope, Kitnayakwa River. Extension Note \# 47 March, 2002. Forest Service, British Columbia, 6 p.

Hamilton, G., Hall, G.C. and Roberts, J. (1974) The Carboniferous non-marine stratigraphy of the Patterson-Gresford District, N.S.W. Journal and Proceedings, Royal Society of N.S.W., Vol.107, pp. 76-86.

Radbruch-Hall, D.H., Colton, R.B., Davies, W.E., Luccietta, I., Skipp, B.A. and Varnes, D.J. (1982) Landslide Overview Map of the Conterminous United States. US Department of the Interior. Geological Survey. Washington, $44 \mathrm{p}$.

Roberts, J. (1961) Geology of the Gresford district, NSW. Royal Society of New South ales- Journal and Proceedings, Vol. 95, pp. 77-91.

Smith, G.K. (2007) Tectonic and Talus Caves at Pilchers Mountain, New South Wales. Helictite, 40(1):1, pp. 1-20.

Sussmilch, C.A. and David, T.W.E. (1920) Sequence, glaciation and correlation of the Carboniferous rocks of the Hunter District. Journal of the Proc. Society of N.S.W., Vol. 53, p. 246.

Watson, R.A. and Wright, H.E. (1963) Landslides on the east flank of the Chuska Mountains, North Western New Mexico. American Journal of Science. Vol. 261, pp. 525-548. 